\title{
Isolated Hepatic Perfusion with Melphalan for Primary or Metastatic Unresectable Cancers of the Liver: Safety and Feasibility in A U.S. Academic Medical Center
}

\author{
Jiping Wang', ${ }^{1,2}$, Martin Hertl',3, A. Benedict Cosimi ${ }^{2,3}$ and Kenneth K. Tanabe ${ }^{2,4 *}$ \\ ${ }^{1}$ Division of Surgical Oncology, Brigham and Women's Hospital, USA \\ ${ }^{2}$ Department of Surgery, Harvard Medical School, USA \\ ${ }^{3}$ Division of Transplant Surgery, Massachusetts General Hospital, USA \\ ${ }^{4}$ Division of Surgical Oncology, Massachusetts General Hospital, USA
}

\begin{abstract}
Background: Although isolated hepatic perfusion (IHP) has been under clinical evaluation for over 50 years, it has not gained wide application due to both the complexity and the insufficient efficacy of the procedure. This study evaluated the feasibility and safety of this procedure at Massachusetts General Hospital.

Methods: Five patients with unresectable primary or metastatic cancer of the liver were included in this study. All patients received 60 minutes IHP with melphalan at $1.5 \mathrm{mg} / \mathrm{kg}$ based upon ideal body weight.

Results: The median operation time was 6 hours and 37 minutes, with the median blood loss of 2 liters. The median hospital stay was 9 days. Two patients experienced grade 4 liver toxicity. One postoperative death was due to multiple organ system failure. One patient experienced disease progression at one month after surgery, two patients had stable disease (5 months) and one patient achieved partial response (8 months).

Conclusion: IHP with melphalan for primary or metastatic unresectable cancers of the liver can be safely performed at an academic medical center outside of NCI surgical branch with comparable toxicity profile. Although the length of hospital stay and toxicity are acceptable, the absence of durable responses tempers enthusiasm for this invasive approach.
\end{abstract}

\section{Background}

Unresectable primary and metastatic cancers of the liver remain a frequent and challenging clinical scenario to both liver surgeons and medical oncologists. In many cancers, the finding of liver metastases is indicative of widespread disease present in several organs. But specific cancers, such as colorectal cancer, ocular melanoma, and neuroendocrine carcinoma commonly metastasize to the liver, without spread to other organs [1-5]. Systemic therapy remains the mainstay of treatment for patients with these conditions; however, because of systemic-toxicity related dosage limitations the efficacy is generally limited. For example, even with aggressive treatment, the median survival in patients with liver metastases from ocular melanoma is between 2 and 7 months [4,6]. While neuroendocrine carcinoma liver metastases sometimes have an indolent biology with a slow rate of growth, poorly differentiated neuroendocrine carcinomas are much more aggressive and are generally associated with a very poor prognosis. With an eye towards development of more effective treatments for malignancies confined to the liver, regional therapies have been an active area of investigation for these metastatic cancers, as well as for intrahepatic cholangiocarcinomas and hepatocellular carcinomas.

Liver directed regional therapies include infusion of therapeutic agents directly into the hepatic artery or portal vein using either percutaneously positioned catheters or an implantable pump; local ablative techniques such as cryotherapy, radiofrequency ablation, or alcohol injection; intratumoral injection of cytotoxic agents; external or internal radiation of tumors; and tumor hyperthermia [7-13]. Therapies administered into the hepatic artery have also been combined with intra-arterial administration of absorbable or non-absorbable particles (chemo-embolization) [14], delivered in lipid emulsions that are selectively retained in tumor [15], or delivered in combination with hemofiltration device to increase drug clearance [16]. None of these treatments have had sufficient established efficacy to the degree that they have been accepted as standard therapy.

Isolated hepatic perfusion has been under clinical evaluation for over 50 years [17]. This technique represents the ultimate refinement in regional treatment strategies by achieving complete isolation of the hepatic circulation from the systemic circulation, thereby exposing liver tumors to extremely high local concentrations of therapeutic agents for prolonged periods of time. This procedure also lowers the risk of systemic toxicity, by confining the major exposure of the therapeutic agent to the liver. Isolated hepatic perfusion also allows for creation of hyperthermic conditions in the liver. Hyperthermia

Correspondence to: Kenneth K. Tanabe, 55 Fruit Street Boston, MA, 02114 Mailstop: Yawkey 7.924, USA, Tel: 617-724-3868; Fax: 617-724-3895; E-mail: KTANABE@partners.org

Key words: colorectal cancer liver metastasis, isolated hepatic perfusion, melphalan Received: June 10, 2017; Accepted: July 20, 2017; Published: July 24, 2017 
enhances cytotoxicity of specific therapeutic agents [18]. Phase I and phase II clinical trials have been conducted in Europe since the 1990s with acceptable morbidity and toxicity [19-21]. Approximately 15 years ago the Surgery Branch at the National Cancer Institute initiated clinical trials of isolated hepatic perfusion with several refinements and modifications to improve the potential safety and efficacy of this treatment technique. The partial response observed in the NCI experience is reported to range from $62 \%$ to $75 \%$ [22-24]. At the time we initiated the clinical trial reported herein, isolated hepatic perfusion had not been performed in the United States outside of the Surgery Branch of the National Cancer Institute. This pilot study was conducted during October, 2003 - October, 2004, to determine whether the technical knowledge and skills for the procedure could be transferred to another center with acceptable operative morbidity and mortality, and to determine the magnitude of resources required to support this procedure.

\section{Patients and Methods}

\section{Patients}

A pilot study of isolated hepatic perfusion (IHP) with melphalan for primary or metastatic unresectable cancers of the liver was approved by the board of human research ethics committee of the Dana-Farber/ Harvard Cancer Center. The protocol was designed to recruit 5 patients and written consent form was obtained from all patients. Patients with unresectable metastatic ocular melanoma, metastatic colon or rectal carcinoma, metastatic islet cell tumors, hepatocellular carcinoma, or cholangiocarcinoma were eligible to participate. Patients with colon or rectal carcinoma liver metastases should have already failed treatment regimens comprised of 5-FU, irinotecan, and/or oxaliplatin. Patients must have had no chemotherapy, radiotherapy, or biologic therapy for their malignancy in the month prior to the liver perfusion and must have recovered from all side effects of previous treatments. Patients were required to have an ECOG performance status of 0,1 or 2 on the day of treatment. Adequate hepatic function as evidenced by bilirubin $<2.0 \mathrm{mg} / \mathrm{dL}$ and a PT within 2 seconds of the upper normal limit was required. Elevations in serum transaminases not due to hepatitis were acceptable. Patients with cirrhosis or evidence of significant portal hypertension were excluded. Patients with a history of congestive heart failure with an LVEF $<40 \%$, with COPD or other chronic pulmonary disease with PFT's $<50 \%$ predicted for age, hepatitis $\mathrm{C}$ or chronic active hepatitis surface antigen $B$ were excluded.

\section{IHP methods}

\section{Extracorporeal bypass circuit}

Patients initially underwent a limited right subcostal laparotomy incision for exploration of the peritoneal cavity to assess the suitability for proceeding with an isolated hepatic perfusion. The subcostal incision was then extended and the liver fully mobilized in a standard fashion. Anterior and posterior phrenic, right adrenal and retroperitoneal veins were ligated to minimize leak of perfusate into the systemic circulation. The portahepatis structures were fully isolated. The axillary vein, saphenous veins and portal vein were cannulated, with catheters connected to an external active centrifugal pump for veno-veno bypass. Blood from lower extremities, kidneys and viscera were bypassed to heart via the axillary vein. After the first patient's operation was conducted in this manner, the protocol was amended to change the technique to percutaneous insertion of cannulas into the femoral vein and either the internal jugular vein or the subclavian vein, and to discontinue the practice of shunting the portal venous drainage into the veno-veno bypass circuit. Once external bypass flow had been established, the retrohepatic vena cava was cannulated with a $20-24$ French venous cannula to collect venous outflow from the hepatic veins during the hepatic perfusion. Subsequently, a $2-4 \mathrm{~mm}$ arterial cannula was introduced into the gastroduodenal artery and positioned for perfusion into the right and left hepatic arteries. Once all cannulas were correctly positioned, vascular clamps were placed across the suprahepatic inferior vena cava just beneath the diaphragm and across the common hepatic artery. Rummel tourniquets were secured around the infrahepatic IVC and proximal portal vein. The veno-veno bypass flow rate was kept at approximately $1200 \mathrm{ml} /$ minute.Flourescein and a Wood's lamp were used for leak monitoring.

Following the isolated hepatic perfusion with melphalan under hyperthermic conditions as described below, the vascular clamps across the common hepatic artery and supra hepatic inferior vena cava were removed to restore arterial flow to the liver with normal venous outflow into the right atrium. The arterial cannula was then removed and the gastroduodenal artery was ligated. The veno-veno bypass cannulas were removed. The hepatic venous return cannula was removed from the infrahepatic inferior vena cava and the venotomy was repaired. The portal vein cannula was removed and the portal venotomy was repaired. . The veno-veno bypass cannulas were removed after autotransfusion of blood from the Biomedicus bypass circuit back into the patient.

\section{Liver perfusion circuit}

The extracorporeal hepatic perfusion circuit consisted of a roller pump, membrane oxygenator and heat exchanger comparable to the extracorporeal circuit used in cardiac surgery procedures. The initial perfusate was a balanced salt solution $(700 \mathrm{ml})$ primed with $300 \mathrm{ml}$ packed red blood cells. Sodium bicarbonate was added to the perfusion circuit during the procedure as needed to maintain an arterial $\mathrm{pH}$ in the range of 7.2 to 7.4. Flow rates were adjusted according to acceptable perfusion line pressures and were typically in the range of $600-1000$ $\mathrm{ml} / \mathrm{min}$. Perfusate temperatures were maintained in the range of 39.5 - 40C and parenchymal liver temperatures were approximately the same. The perfusion proceeded for 60 minutes. At the completion of the perfusion, the liver was flushed via the perfusion circuit with 1,500 cc of saline and $1,500 \mathrm{cc}$ of hespan. The portal vein was flushed with 1 liter of normal saline through a separate cannula and flush system.

\section{Melphalan}

The dose of melphalan administered via isolated hepatic perfusion in this study was selected based upon the maximum safe tolerated dose as defined in a previous Phase I hepatic perfusion trial (NCI 97-C0200). The dose was $1.5 \mathrm{mg} / \mathrm{kg}$ administered based upon ideal body weight males: $50 \mathrm{~kg}$ plus $2.3 \mathrm{~kg}$ for every inch over 5 feet; females: $45.5 \mathrm{~kg}$ plus $2.3 \mathrm{~kg}$ for every inch over 5 feet.

The minimum and maximum total dose of melphalan was 90 and $120 \mathrm{mg}$, respectively. The dose of melphalan was delivered into a 1 liter circuit volume and was further diluted by the blood volume in the liver.

\section{Toxicity and complication}

Toxicity data were collected and graded using the National Cancer Institute common toxicity criteria version 2.0. Hepatic toxicities were considered treatment related if the abnormality continued beyond 7 days after IHP [22]. Any post-operative complication were prospectively collected and reported.

\section{Tumor response}

Tumor response was evaluated with imaging studies (CT or MRI) by using Response Evaluation Criteria In Solid Tumors (RECIST). 
Complete Response (CR) is defined as the disappearance of all target lesions. Partial Response (PR) is defined as at least a $30 \%$ decrease in the sum of the largest dimension (LD) of target lesions, taking as reference the baseline sum LD. Stable Disease (SD): Neither sufficient shrinkage to qualify for PR nor sufficient increase to qualify for progressive disease, taking as reference the smallest sum LD since the treatment started. Progressive Disease (PD): At least a 20\% increase in the sum of the LD of target lesions, taking as reference the smallest sum LD recorded since the treatment started or the appearance of one or more new lesions

\section{Statistical Analysis}

All patients' demographic and clinical characteristics and toxicity were reported with descriptive statistics. The treatment parameters were reported with median and range. The treatment effects were listed by each individual patient. The median survival was estimated using Kaplan-Meier method. All the statistical analysis was conducted with SAS 9.2.

\section{Result}

\section{Patients demographic and tumor characteristics}

Five patients including 1 female and 4 male were included in this study. Two patients had ocular melanoma liver metastases. The other three patients had liver metastases from rectal cancer, pancreatic cancer and cholangiocarcinoma. The median age was 61 years with the range of 53 - 77 years (Table 1).

\section{Treatment parameters and complications}

All patients received the full 60 minutes of IHP with melphalan as per protocol. The median dose was $110 \mathrm{mg}$ with the range of $92-120 \mathrm{mg}$. The median operation time was 6 hours and 37 minutes, with the median blood loss of 2 liters (the majority of which consisted of effluent from the hepatic veins during the wash phase, which was discarded). The median hospital stay was 9 days. Three patients developed pleural effusions, and two of them required chest tube drainage. Reintubation for respiratory failure was observed in two patients. Renal insufficiency, mental status change, ascites, sepsis and clostridium difficile infection, each occurred once (Table 2). Liver toxicity as assessed biochemically is presented in Figure 1 and Table 3. Alkaline phosphase levels dropped quickly below the pre-operative levels. Total bilirubin level dropped below 2 within 7 days post operation except for one patient, who developed rapid onset liver failure and septic shock within 2 weeks post operatively and died at post-operative day 17. The AST and ALT took longer to return to pre-operative levels with the median value of 146 units and 120 units at the end of post-operative day 7 respectively. Two patients experienced transient grade 4 liver toxicity. None of the patients had renal function impairment from the IHP (Table 4).

Table 1. Patient and tumor characteristics

\begin{tabular}{|l|l|l|}
\hline Number of patients & \multicolumn{1}{l|}{$\mathbf{5}$} \\
\hline Age in years, median (range) & Rectal & 61 (53-77) \\
\hline \multirow{3}{*}{ Primary Cancer } & Pancreatic & 1 \\
\cline { 2 - 3 } & Occular Melanoma & 1 \\
\hline \multirow{2}{*}{ Gender } & Cholangio & 2 \\
\hline & F & 1 \\
\hline & M & 1 \\
\hline
\end{tabular}

Table 2. Treatment parameters and complications

\begin{tabular}{|c|c|c|}
\hline \multicolumn{2}{|l|}{ OR time (min) } & $397(370-532)$ \\
\hline \multicolumn{2}{|l|}{$* \operatorname{EBL}(\mathrm{L})$} & $2(2-9)$ \\
\hline \multicolumn{2}{|l|}{ Liver temp $\left(\mathrm{C}^{\circ}\right)$} & $40(39.5-40)$ \\
\hline \multicolumn{2}{|l|}{ Melphalan does (mg) } & $110(92-120)$ \\
\hline \multicolumn{2}{|l|}{ Transfusion (unit) } & $4(2-18)$ \\
\hline \multicolumn{2}{|l|}{ Perfusion rate $(\mathrm{ml} / \mathrm{min})$} & $800(625-950)$ \\
\hline \multicolumn{2}{|l|}{ Bypass rate (ml/min) } & $2000(1200-2500)$ \\
\hline \multicolumn{2}{|c|}{ Length of ICU stay (days) } & $1(1-17)$ \\
\hline \multicolumn{2}{|c|}{ Length of hospital stay (days) } & $9(6-17)$ \\
\hline \multirow{8}{*}{ Complications } & Death & 1 \\
\hline & Pleural effusion & 3 \\
\hline & Renal failure & 1 \\
\hline & Respiratory distress/failure & 2 \\
\hline & Mental status change & 1 \\
\hline & Ascites & 1 \\
\hline & Sepsis & 1 \\
\hline & Clostridium Dificile Colitis & 1 \\
\hline
\end{tabular}

*Include discarded blood from perfusion circuit.

Table 3. Treatment results.

\begin{tabular}{|c|c|c|c|}
\hline Patient & Hepatic response & $\begin{array}{c}\text { Time to progression } \\
\text { (months) }\end{array}$ & $\begin{array}{c}\text { Time to death or last } \\
\text { follow-up (months) }\end{array}$ \\
\hline 1 & - & - & 0.6 \\
\hline 2 & PD & 1.4 & 3.7 \\
\hline 3 & PR & 8.1 & 12.4 \\
\hline 4 & SD & 5.3 & 8.1 \\
\hline 5 & SD & 5.8 & 20 \\
\hline
\end{tabular}

*PD: progressive disease; PR: partial response; SD: stable disease.

Table 4. Toxicity for Postoperative Day 1.

\begin{tabular}{|c|c|c|c|c|c|}
\hline & Grade0 & Grade1 & Grade2 & Grade3 & Grade4 \\
\hline ALP & 4 & 1 & 0 & 0 & 0 \\
\hline ALT & 0 & 1 & 1 & 1 & 2 \\
\hline AST & 0 & 0 & 0 & 5 & 0 \\
\hline Bilirubin & 3 & 0 & 1 & 1 & 0 \\
\hline Cr & 5 & 0 & 0 & 0 & 0 \\
\hline
\end{tabular}

*ALP: Alkaline phosphatase, SGPT: Serum glutamic pyruvic transaminase, SGOT: Serum glutamic oxaloacetic transaminase, Cr: creatinine

\section{Tumor responses}

One patient experienced disease progression at one month, two patients had stable disease and one patient achieved partial response. The time to progression for 4 measurable patients were 1.4, 5.3, 5.8 and 8.1 months and the median time to death or last follow-up were 8.1 months with the range of 0.6 to 20 months (Table 3).

\section{Discussion}

Our observations in this pilot study demonstrated that isolated hepatic perfusion with melphalan for primary or metastatic unresectable cancers of the liver can be safely performed at an academic center outside of NCI surgical branch with comparable toxicity profile. Although this study was designed to evaluate primarily the toxicity and feasibility of this treatment modality as well as the magnitude of resources required, observations were that three of the five patients 

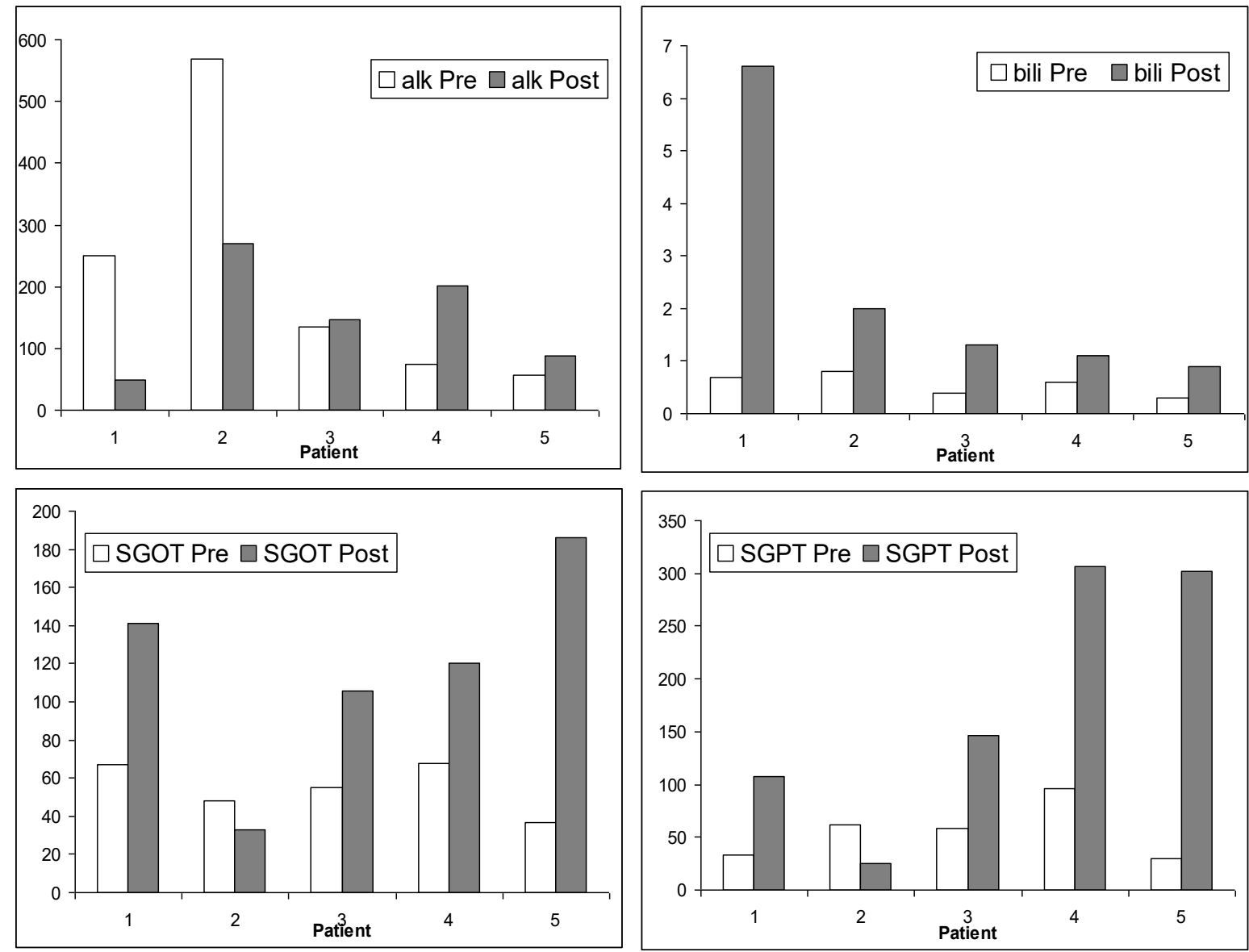

*The results of liver function tests (LFT) within 7 days post operation were used for the comparison.

Figure 1. Liver function change between preoperative and within 7 days post-operative*

experienced partial response and one had stable disease. The range of time to death or last follow-up was 3.7 to 15.6 months (excluding the perioperative death case). Admitting there is no randomized clinical trial to compare the efficacy of IHP and various regional treatment strategies including direct intra-arterial chemotherapy, chemoembolization and cryotherapy, IHP does have several theoretical advantages. Compares with intra-arterial chemotherapy and chemoembolization, IHP establishes a near complete vascular isolation of the liver, allowing delivery of higher doses of chemotherapeutic agents, which will create intolerable toxicity and produce significant morbidity and mortality if given via the systemic circulation. Furthermore, unlike cryotherapy, IHP is not as limited by the number and the size of metastatic loci and has the potential to treat subclinical/microscopic disease. The high response rate $(62 \%-83 \%)$ of IHP makes it a very attractive procedure to patients with limited choices of alternative therapy.

However, there are several issues that hamper the wider implementation of this procedure. First, it is a time consuming, resources intensive and expensive procedure that requires multiple surgeons familiar with liver surgery, veno-veno bypass, hyperthermia and regional therapy. Our experience indicated that a team approach is needed to carry out the procedure and the median operation time is over 6 hours. It typically requires two attending HBP surgeons rather than an attending and a resident; perfusionists; an anesthesia team who is comfortable with veno-veno bypass; and an ICU team familiar with the post-operative hemodynamics and liver function changes. Second, it is a complex procedure with higher risks of complications, morbidity and mortality. The common morbidity and toxicity including bleeding (3\%), pleural effusion (7\%-15\%), atrial fibirlation/arrythymia (5\%-8\%), ascites $(2.5 \%-8 \%)$, renal failure $(8 \%)$, wound infection $(2.5 \%-8 \%)$ and liver function derangements (56\%-62\%) [25-27]. The post-operative mortality ranges from $3.3 \%$ to $22.2 \%$ [26,28]. In our series, 3 patients (60\%) developed pleural effusion and two patients required chest tube placements. All the patients experienced grade 3 or 4 liver toxicity (derangement of alkaline phosphase, AST or ALS), although, this disturbance resolved reasonably well within 2 weeks after surgery. One of the patients experienced renal failure after other stressful events. $\mathrm{He}$ experienced respiratory distress after extubation at post-operative day one and required re-intubation at post-operative day four. The same patient died 17 days after surgery with multiple organ system failure. This patient was the first subject in our series and had much more of his liver replaced by tumor than was recognized on scans, which were performed 6 weeks prior to the operation. This outcome lead to changes in the protocol, the most notable of which were restriction of the liver tumor burden to less than half of the liver volume, and requirement of eligibility scans to be within 4 weeks of the procedure. The subsequent patient expressed signs of fluid overload, pleural effusion required chest tube placement, renal failure, clostridium difficile infection and septic shock. Third, although IHP offered relative high response rate, the efficacy profile is still unsatisfactory. For colorectal cancer liver metastasis patients, the response rate can reach to $77 \%$ [29], however the median survival remains in the ranges of 10.3 months to 27 months dependant on the patient population selected for study, regimens used, 
and modality (IPH with/without HAI) $[19,29,30]$. On the other hand, for patients receiving systemic chemotherapy with standard cytotoxic drugs (FOLFOX or FOLFIRI), a median survival time of 20 months can be achieved [31-34]. Iersel et al reported their case-control study in evaluating the efficacy of IHP versus systemic chemotherapy based on 200 patients [35]. The response rates were $47 \%$ and $41 \%$ for IHP and systemic chemotherapy respectively. The median survival was 25 months for the patients who received IHP and 21.7 months for the patients who were treated with systemic chemotherapy only $(\mathrm{p}=0.29)$.

Percutaneous isolated liver perfusion(ILP) using BoddenGlickman catheter, Delcath system or other similar catheter system has been proposed with the aim of reducing the complexity of the IHP and corresponding morbidity and mortality [16,36-38]. Using this technique, complete isolation of the liver is not obtained as the portal vein is not occluded during the ILP. The liver is perfused in antegrade flow and the venous blood, drained from the liver, passes through charcoal filters to absorb the residual chemotherapeutic drugs before being reinfused via the internal jugular vein. According to the report from Pingpank et al. [38], complete extraction of melphalan by charcoal hemofiltration is not possible. Other limitations of this approach include the absence of hyperthermic conditions and catecolamine depletion due to the filtration. Sometimes, the relative anatomic location of IVC, hepatic vein and right atrium precludes the application of the catheter. Pingpank et al reported their experience in treating metastatic ocular melanoma with ILP at 2010 ASCO meeting. Although the response rates and hepatic progression survival determined by RECIST were significantly different between the ILP group and the best-of-care comparison group, the overall survival benefit and the IHP associate morbidity were not reported.

In summary, local therapy via hepatic perfusion is one of the alternative methods to treat primary or metastatic unresectable liver tumor with evidence of encouraging tumor response, but associated significant morbidity, and limited survival benefit. For colorectal cancer liver metastasis patients systemic chemotherapy has been shown to achieve similar clinical outcomes with less morbidity. The procedure is expensive and resource intensive. Further research is needed to develop less toxic perforates, which can increase response rate, duration of response and overall survival. Until this is accomplished, IHP should remain in the clinical trial setting.

\section{References}

1. Kath R, Hayungs J, Bornfeld N, Sauerwein W, Höffken K, et al. (1993) Prognosis and treatment of disseminated uveal melanoma. Cancer 72: 2219-2223. [Crossref]

2. Seregard S, Kock E (1995) Prognostic indicators following enucleation for posterior uveal melanoma. A multivariate analysis of long-term survival with minimized loss to follow-up. Acta Ophthalmol Scand 73: 340-344. [Crossref]

3. Penna C, Nordlinger B (2002) Colorectal metastasis (liver and lung). Surg Clin North Am 82: 1075-1090. [Crossref]

4. Bedikian AY, Legha SS, Mavligit G, Carrasco CH, Khorana S, et al. (1995) Treatment of uveal melanoma metastatic to the liver: a review of the M. D. Anderson Cancer Center experience and prognostic factors. Cancer 76: 1665-1670. [Crossref]

5. Berge T, Linell $\mathrm{F}$ (1976) Carcinoid tumors. frequency in a defined population during a 12-year-period. Acta Pathol Microbiol Scand A 84: 322-330. [Crossref]

6. Rajpal S, Moore R, Karakousis CP (1983) Survival in metastatic ocular melanoma. Cancer 52: 334-336. [Crossref]

7. Kim BK, Park JY, Choi HJ, Kim DY, Ahn SH, et al. (2011) Long-term clinical outcomes of hepatic arterial infusion chemotherapy with cisplatin with or without 5-fluorouracil in locally advanced hepatocellular carcinoma. J Cancer Res Clin Oncol 137: 659-667. [Crossref]
8. Yip WM, Hung HG, Lok KH, Li KF, Li KK, et al. (2009) Outcome of inoperable hepatocellular carcinoma patients receiving transarterial chemoembolisation: a real-life retrospective analysis in a Hong Kong regional hospital. Hong Kong Med J 15: 339345. [Crossref]

9. Morris DL, Ross WB (1996) Australian experience of cryoablation of liver tumors: metastases. Surg Oncol Clin N Am 5: 391-397. [Crossref]

10. Lencioni R, Crocetti L (2007) Radiofrequency ablation of liver cancer. Tech Vasc Interv Radiol 10: 38-46. [Crossref]

11. Kiba T, Numata K, Kitamura T, Morita K, Saito S, et al. (2001) Combination therapy of percutaneous mitoxantrone injection, percutaneous ethanol injection, and transcatheter arterial embolization for intrahepatic hepatocellular carcinoma and adrenal metastasis. Hepatogastroenterology 48: 427-431. [Crossref]

12. Seo YS, Kim MS, Yoo SY, Cho CK, Choi CW, et al. (2010) Preliminary result of stereotactic body radiotherapy as a local salvage treatment for inoperable hepatocellular carcinoma. J Surg Oncol 102: 209-214. [Crossref]

13. King J, Quinn R, Glenn DM, Janssen J, Tong D, et al. (2008) Radioembolization with selective internal radiation microspheres for neuroendocrine liver metastases. Cancer 113: 921-929. [Crossref]

14. Soulen MC (1994) Chemoembolization of hepatic malignancies. Oncology (Williston Park) 8: 77-84. [Crossref]

15. Groupe d'Etude et de Traitement du Carcinome Hépatocellulaire (1995) A comparison of lipiodol chemoembolization and conservative treatment for unresectable hepatocellular carcinoma. $N$ Engl J Med 332: 1256-1261. [Crossref]

16. Ravikumar TS, Pizzorno G, Bodden W, Marsh J, Strair R, et al. (1994) Percutaneous hepatic vein isolation and high-dose hepatic arterial infusion chemotherapy for unresectable liver tumors. J Clin Oncol 12: 2723-2736. [Crossref]

17. Ausman RK, Aust JB (1960) Isolated perfusion of the liver with HN2. Surg Forum 10 77-79. [Crossref]

18. Urano M, Ling CC (2002) Thermal enhancement of melphalan and oxaliplatin cytotoxicity in vitro. Int J Hyperthermia 18: 307-315. [Crossref]

19. de Vries MR, Borel Rinkes IH, van de Velde CJ, Wiggers T, Tollenaar RA, et al (1998) Isolated hepatic perfusion with tumor necrosis factor alpha and melphalan: experimental studies in pigs and phase I data from humans. Recent Results Cancer Res 147: 107-119. [Crossref]

20. de Wilt JH, van Etten B, Verhoef C, Eggermont AM (2004) Isolated hepatic perfusion experimental evidence and clinical utility. Surg Clin North Am 84: 627-641. [Crossref]

21. Hafström LR, Holmberg SB, Naredi PL, Lindnér PG, Bengtsson A, et al. (1994) Isolated hyperthermic liver perfusion with chemotherapy for liver malignancy. Surg Oncol 3: 103-108. [Crossref]

22. Alexander HR Jr, Bartlett DL, Libutti SK, Fraker DL, Moser T, et al. (1998) Isolated hepatic perfusion with tumor necrosis factor and melphalan for unresectable cancers confined to the liver. J Clin Oncol 16: 1479-1489. [Crossref]

23. Alexander HR Jr, Bartlett DL, Libutti SK (1998) Isolated hepatic perfusion: a potentially effective treatment for patients with metastatic or primary cancers confined to the liver. Cancer J Sci Am 4: 2-11.

24. Alexander HR, Libutti SK, Bartlett DL, Puhlmann M, Fraker DL, et al. (2000) A phase I-II study of isolated hepatic perfusion using melphalan with or without tumor necrosis factor for patients with ocular melanoma metastatic to liver. Clin Cancer Res 6: 30623070. [Crossref]

25. Alexander HR, Libutti SK, Pingpank JF, Steinberg SM, Bartlett DL, et al. (2003) Hyperthermic Isolated Hepatic Perfusion Using Melphalan for Patients with Ocular Melanoma Metastatic to Liver. Clin Cancer Res 9: 6343-6349. [Crossref]

26. Alexander H, Bartlett DL, Libutti SK, Pingpank JF, Fraker DL, et al. (2009) Analysis of Factors Associated with Outcome in Patients Undergoing Isolated Hepatic Perfusion for Unresectable Liver Metastases from Colorectal Center. Ann Surg Oncol 16: 1852 1859. [Crossref]

27. Grover AC, Libutti SK, Pingpank JF, Helsabeck C, Beresnev T, et al. (2004) Isolated hepatic perfusion for the treatment of patients with advanced liver metastases from pancreatic and gastrointestinal neuroendocrine neoplasms. Surgery 136: 1176-1182. [Crossref]

28. Rizell M, Mattson J, Cahlin C, Hafström L, Lindner P, et al. (2008) Isolated hepatic perfusion for liver metastases of malignant melanoma. Melanoma Res 18: 120-126. [Crossref] 
29. Bartlett DL, Libutti SK, Figg WD, Fraker DL, Alexander HR, et al. (2001) Isolated hepatic perfusion for unresectable hepatic metastases from colorectal cancer. Surgery 129: 176-187. [Crossref]

30. Grover A, Alexander HR Jr (2004) The past decade of experience with isolated hepatic perfusion. Oncologist 9: 653-664. [Crossref]

31. Narang AS, Cheng K, Henry J, Zhang C, Sabek O, et al. (2004) Vascular endothelial growth factor gene delivery for revascularization in transplanted human islets. Pharm Res 21: 15-25. [Crossref]

32. Bhagwagar Z, Wylezinska M, Jezzard P, Evans J, Boorman E, et al. (2008) Low GABA concentrations in occipital cortex and anterior cingulate cortex in medication-free, recovered depressed patients. Int J Neuropsychopharmacol 11: 255-260. [Crossref]

33. Falcone A, Ricci S, Brunetti I, Pfanner E, Allegrini G, et al. (2007) Phase III trial of infusional fluorouracil, leucovorin, oxaliplatin, and irinotecan (FOLFOXIRI) compared with infusional fluorouracil, leucovorin, and irinotecan (FOLFIRI) as firstline treatment for metastatic colorectal cancer: the Gruppo Oncologico Nord Ovest. $J$ Clin Oncol 25: 1670-1676. [Crossref]
34. Tournigand C, André T, Achille E, Lledo G, Flesh M, et al. (2004) FOLFIRI followed by FOLFOX6 or the reverse sequence in advanced colorectal cancer: a randomized GERCOR study. J Clin Oncol 22: 229-237. [Crossref]

35. van Iersel LB, Koopman M, van de Velde CJ, Mol L, van Persijn van Meerten EL, et al. (2010) Management of isolated nonresectable liver metastases in colorectal cancer patients: a case-control study of isolated hepatic perfusion with melphalan versus systemic chemotherapy. Ann Oncol 21: 1662-1667. [Crossref]

36. Maleux G, Monbaliu D, Verslype C, Casteleyn C, Van De Velde M, et al. (2010) Percutaneous isolated liver perfusion with occlusion balloons and a catheter-based stent-graft-like perfusion device: an experimental study in a porcine model. Eur Radiol 20: 2372-2380. [Crossref]

37. Beheshti MV, Denny DF Jr, Glickman MG, Bodden W, Marsh JC, et al. (1992) Percutaneous isolated liver perfusion for treatment of hepatic malignancy: preliminary report. J Vasc Interv Radiol 3: 453-458. [Crossref]

38. Pingpank JF, Libutti SK, Chang R, Wood BJ, Neeman Z, et al. (2005) Phase study of hepatic arterial melphalan infusion and hepatic venous hemofiltration using percutaneously placed catheters in patients with unresectable hepatic malignancies. $J$ Clin Oncol 23: 3465-3474. [Crossref]

Copyright: (C2017 Wang J. This is an open-access article distributed under the terms of the Creative Commons Attribution License, which permits unrestricted use, distribution, and reproduction in any medium, provided the original author and source are credited. 